\title{
TCOM \\ Communicating science in English: a preliminary exploration into the professional self-perceptions of Australian scientists from language backgrounds other than English
}

\section{Adam Huttner-Koros and Sean Perera}

Abstract

Keywords

Introduction
Scientists for whom English is not their first language report disadvantages with academic communication internationally. This case study explores preliminary evidence from non-Anglophone scientists in an Australian research organisation, where English is the first language. While the authors identified similarities with previous research, they found that scientists from non-Anglophone language backgrounds are limited by more than their level of linguistic proficiency in English. Academic science communication may be underpinned by perceptions of identity that are defined by the Anglocentric hegemony in science, which dictates not only how academic science is communicated but also who can communicate it.

Professionalism, professional development and training in science communication, Scholarly communication, Social inclusion

\subsection{Preeminent role of English in science}

English is not just an international language of communication. Its function as a communication conduit between otherwise non-mutually intelligible languages privileges English as both a facilitator and gatekeeper of information exchange. As early as 1996, Dunbar stated, "English has spread around the globe to become the lingua franca of trade, government and science, as well as the national language of countries on every continent" [1996, pp. 157-8].

In science, English is the most commonly used language of communication [Crystal, 2003]. The "predominance" of English in academic scientific research is acknowledged internationally [Swales, 1990, p. 99]. While a linguistic hegemony of this type has not been seen previously in human history [Shweder, 2012], language scholars claim that an important justification for the preeminent role of English in science is the assumption of its cultural neutrality [Wierzbicka, 2014]. Science communicated in English is assumed not to imply any socio-cultural bias, contrary to historical evidence extending far back to seventeenth century England, where Baconian ideologies and subsequent efforts by the Royal Society attempted to protect science from the unreliability of rhetoric [Bauman and Briggs, 2003]. Recent 
studies have shown that school students already perceive a gap between "culture" and "science", where "culture" does not have any connection to science and is mainly a feature of people's identity based on skin colour [Gondwe and Longnecker, 2015].

Communicating science in English promotes, nonetheless, norms of describing and defining the natural world that are intrinsic to the English language, and ideologies that are conversant to its native speakers, such as having an opinion or a sense of right versus wrong, as Wierzbicka [2014] explains:

Every language is a repository of unique ways of thinking about human existence and a unique cultural "take" on human existence, and in particular on human values. But we will not recover these unique cultural perspectives on values by interpreting them through the prism of English value words and Anglo cultural scripts. [p. 61]

Sacks [1996] explains further that different languages may place more or less emphasis on different socio-cultural aspects, depending on the distinctions of its users. The English language is not immune to this linguistic phenomenon known as forms of attention. However, native speakers of English are often oblivious to these distinctions, and their familiarity with those elements of Anglophone culture can result in Anglocentric terminology in science. English language-based technical terminology in science typifies, therefore, the way Anglophone scholars think, and does not, necessarily, portray the social cognition of other language speakers [Wierzbicka, 2014, p. 128]. According to Harré [2012]:

There is a great diversity of languages and each is the bearer of core features of the culture in which it is used... The way the users of particular languages think, act, feel and perceive is shaped by their cultural inheritance, of which a major component is their mother tongue. [p. 22]

For instance, the South Asian languages Sinhalese and Kota do not possess lexical equivalents to the English word depression [Obeyesekere, 1985]. Yet, as Dowrick [2004] has demonstrated, native English speakers assume that depression, when used in the context of mental health, can be translated by speakers of other languages universally to mean the same psychiatric diagnosis. In another example, Vass, Mitchell and Dhurrkay [2011] found that communicating health information to Indigenous Australian people, whose first language is not English, relied on awareness of their languages and worldviews. A study of the Yolnu people in Northern Territory, for example, revealed that their concept of health "is a comprehensive entity of wellbeing that is linked with land, law and relationships" [p. 36], and that they did not have a word corresponding to the English meaning of health.

\subsection{Scientists from other language backgrounds}

A short space needs to be devoted here to explain the other, with regard to scientists not identifying as natively Anglophone. The accepted dictionary definition for Anglophone is an individual who identifies as belonging to an English-speaking 
population [Merriam-Webster, 2016] making it possible, therefore, to describe the other as Non-English Speaking Background (NESB), and Language Backgrounds Other Than English (LBOTE). In attempting to accurately describe the other, literature abounds with counterpart terms to native English speaker and first language English speaker. These include Non-native English Speaker, speakers of English as a Second Language (ESL), and speakers of English as an Additional Language or Dialect (EALD). These terms are used interchangeably to identify and define the other. We have continued this practice in this paper, drawing from the above terminology to differentiate scientists who do not identify as Anglophone.

\subsection{Academic science communication by non-Anglophone scientists}

Projecting science through an Anglocentric lens can also influence how science is conducted. In particular, it raises concerns about the impact of Anglocentric science communication on people from non-Anglophone backgrounds. Several decades ago, Goonatilake [1987] argued that in the Third World, scientists from language backgrounds other than English are trained to communicate with syntax and imagery to benefit Anglophone audiences:

Third World scientists are led to speak and write primarily to and for an audience of Western listeners and readers; the intellectual and technological world systems make it unreasonable for them to be primarily interested in Third World (i.e. their own) audiences. [p. 890]

A corollary of this phenomenon is an expanding body of academic science communication in English by non-native speakers of the language. As Mauranen, Hynninen and Ranta [2010] have found, academic publication of scientific research in English is a space in which the contributing majority are scientists from non-English speaking backgrounds, yet it remains a purview defined by Anglophone scientists. Because access to this space is controlled linguistically, it deprives scientists from language backgrounds other than English from participating equally, including scientists from other post-industrial European nations [Van Leeuwen et al., 2001]. Evidence suggests, for instance, that scientific research conducted in Germany, France and Switzerland, that was not published in English, did not receive due recognition in Science Citation Indices; presuming, thereby, an exclusivity for English in academic science communication [Meneghini and Packer, 2007].

What, therefore, compels scientists from other language backgrounds to communicate predominantly in English? Three responses are offered in the literature. First is the assumption that some disciplinary aspects of science can only be communicated in English. As established earlier with reference to Wierzbicka [2014], it is believed by some that objectivity, impartiality and the empirical essence endemic to science could only be conveyed accurately in the English language. It presumes the absence of comparable ideologies in other languages; and if they do exist, that they must correspond to an English lexical equivalent [Dowrick, 2004]. In fact, studies have looked at the variation in styles of English academic discourse in different countries [Bennett, 2010], and provided "concrete evidence of the existence of alternative ways of construing knowledge" [p. 22]. 
Second is the belief that scholarly scientific communication is best achieved through the English language. This is evidenced, as Van Leeuwen et al. [2001] pointed out previously, by non-Anglophone European scientists increasingly communicating their scientific research in Anglophone journals. Similar trends have been recorded in Hong Kong [see Flowerdew, 1999b], where scientists clearly believe that it is important to produce academic scientific work in English. In South Korea, Hwang [2005] found that scientists' perceived importance of academic communication in English causes them to expend extra resources to develop proficiency in the language, to the extent that certain senior South Korean scientists even relocate temporarily to relatively junior positions in research institutions in English speaking countries. They believe, genuinely, that the opportunity to conduct research in an Anglophone environment enables better communication of their research.

Third, a pragmatic reason, is that academic publications in English advance the careers of scientists, especially in countries where English is not the first language. In Norway, for example, Ljosland [2011] found that scientists who published their research in English believed it offered them an advantage over their peers who published in Norsk. Reinforcing this view is the prevalence of scientific journals in English, with greater Science Citation Indices, compared to those in other languages [Van Leeuwen et al., 2001]. Similarly, scientists in Hong Kong believed that scholarly publications in English affected their careers positively. It was crucial for them, therefore, to communicate their research effectively in English in order to secure publication in Anglophone journals [Flowerdew, 1999b].

Underpinning the above reasons sit two elements that are unique to scientists from language backgrounds other than English. These are the challenges they encounter, and the assistance they seek, to communicate science proficiently. Their perceptions of English language proficiency are, however, gauged relative to native English speakers. As [Flowerdew, 1999a] notes for example, scientists in Hong Kong believe they lack the innate linguistic capabilities of Anglophone scientists, which they perceive are necessary to communicate effectively in English. These frustrations were expressed by one of Flowerdew's interview respondents as follows:

\footnotetext{
No matter what, you cannot express as good as the native speakers...I come to the concept that my expression skills are inferior to them... When you are thinking what to write, you are just creating an idea. But when they think what to write, they already are building up their words and expression skills. That's why it is different. It doesn't matter whether I am using Chinese or English while thinking. But the outcome would not be that coherent or articulate... And I will always have that feeling that I don't express as good as them. [pp. 254-255]
}

Hwang [2013] adds, with reference to scientists in South Korea, that "those lacking language proficiency tend to feel frustrated, experience a sense of professional loss, and have difficulty maintaining dignity" [p. 9]. She has expressed deep concerns [see Hwang, 2005] that these attitudes of despair could "systematically reduce Korea's international competitive ability because of the time and energy that English study requires" [p. 409]. 
Finally, it is important to note that Ferguson, Pérez-Llantada and Plo [2011, p. 43]

have pointed out "the problematic nature of a coarse native-non-native dichotomy in matters of academic publication." They rightly point out that academic English is a challenge for all authors, and that many factors including academic experience are involved in the difficulties of academic publication. The assumption that non-native speakers of English, such as the Spanish scientists of their study, are automatically disadvantaged by their language background, needs to be considered with a "more nuanced, more circumspect view of linguistics disadvantage, language being a hampering factor ... one that in combination with others can amount to a significant obstacle." [p. 43]

\subsection{Professional identity and English language proficiency}

The emphasis on developing effective academic science communication skills can lead to a strong relationship between perceived English language proficiency and professional identity. As Charles [2007] points out, professionals could question their disciplinary expertise in relation to their perceived linguistic proficiency comparable to native English speakers in their profession [see also Jameson, 2007]. Non-Anglophone scientists may struggle, therefore, to maintain professional dignity if they see themselves less able to communicate science academically in English, resulting in a conflict in how they self-perceive their efficacy as scientists [Baumeister, Shapiro and Tice, 1985]. These studies suggest, therefore, a science communication space in which the medium of communication, that is the English language, not only controls [Mauranen, Hynninen and Ranta, 2010], but also confronts, the contributing majority in that space, namely, scientists from non-English speaking backgrounds.

The literature reviewed thus far has only explored this space from the perspectives of scientists located in non-Anglophone societies; viz. France, Germany, Hong Kong, Norway, South Korea, Spain, Sweden and Switzerland. While, Hwang [2005] does describe scientists working in English speaking countries, their relocation outside South Korea is temporary; as are, for example, Myles and Cheng's [2003] findings of international students in Anglophone universities. We suggest that this communication space offers other vantage points that need to be explored. In particular, there appears to be a gap in the literature regarding academic communication by non-Anglophone scientists relocating permanently to countries where English is the first language. We believe there are perspectives to be gained from these scientists, who are required to function exclusively in an English language environment, although English is not their first language. It was the aim of the case study described below to investigate those perspectives and to add depth to previous research documenting academic communication in English by non-Anglophone scientists. To this aim, we investigated the views and experiences of scientists in Australia's largest government-funded research organisation, the Commonwealth Scientific and Industrial Research Organisation (CSIRO). Census, more than a quarter (i.e. 27.7\%) of Australia's population was born overseas, hailing from over 200 countries and speaking over 300 languages at home [ABS, 2014]. As a nation reliant on immigration for its future prosperity [Australian 
Government, 2012], linguistic diversity is and will be an important element of the Australian population.

A recent national survey found, moreover, that the Australian general public relies on its scientists to inform decisions about important matters such as health and nutrition, the environment, and energy production [Searle, 2014]. The survey reported:

From a presented list of nine different types of people, scientists were the most trusted groups of people to explain the impacts of scientific or technological advances. The most trusted of the different groups tested were well known scientists such as Nobel Prize winners or Australians of the Year $(82 \%)$, followed by CSIRO scientists (78\%) and Australia's Chief Scientists (75\%). [p. 5]

In addition, an unprompted, open-ended question in the above survey found that the Australian public recognised CSIRO as one of "the most commonly mentioned trusted sources of accurate information about science" [p. 5]. Since CSIRO communicates scientific information entirely in English, it is necessary to understand the communication issues of the non-Anglophone scientists who play a role in producing that information.

CSIRO is Australia's national science agency with funding over 1 billion dollars, and it is influential in informing national policy and public opinion. Through scientific research undertaken in a series of National Flagships, CSIRO communicates scientific information on topics that include agriculture, nutrition, ecosystem management, mineral resource productivity, and biosecurity [CSIRO, 2015]. Moreover, CSIRO has an active Equal Opportunity Program, mandated by the Australian Government, to ensure equitable employment of staff, including scientists, regardless of race and ethnic origins.

Therefore, CSIRO offered us an ideal space to investigate non-Anglophone scientists' communication in Australia. We recognise the impact and influences the specific culture of an organisation may have on communication practices of its staff [Hwang, 2013], and therefore locating the study within a single organisation minimised the possibility of external cultural differences affecting its outcomes [Hofstede, 2001].

\subsection{Research methods}

Following trends in the literature described earlier [Flowerdew, 1999a; Flowerdew, 1999b; Hwang, 2005; Ljosland, 2011], we decided to explore perspectives about English language based science communication from non-Anglophone scientists who have immigrated to Australia and currently work at CSIRO. Consistent with the exploratory nature of the present study, a qualitative case study approach was used to investigate the following broad research question:

What linguistic, socio-cultural and career issues affect English language-based scientific communication by non-Anglophone scientists at CSIRO? 
It was the aim of this study to probe more deeply the issues underpinned by previous research into academic communication in English by non-Anglophone scientists. Therefore, research investigations guided by the above question focussed on the perceptions of Anglocentric worldviews and assumptions of cultural neutrality in science; in particular, how these affected the professional self-perceptions of the non-Anglophone scientists at CSIRO.

The investigations were contextualised in discussions with four CSIRO Communication Expert staff tasked with advising, facilitating and assisting the Organisation's research communications. The discussion topics included the communication culture at CSIRO and existing structures to support scientists' communication, in particular, scientists from non-Anglophone backgrounds.

The investigation was carried out in two phases. In the first phase, an electronic survey was distributed to scientists employed in CSIRO offices in four locations across Australia: the Australian Capital Territory, New South Wales, Queensland, and Western Australia. The electronic survey, once forwarded to CSIRO, was circulated to the scientists via an internal mailing list. This method, required by the Organisation, was to minimise external disruptions to regular work that may have been caused by circulating the survey more than once. The survey responses relied, therefore, on the voluntary participation of CSIRO scientists who self-identified as non-native English speakers. Self-identification as a non-native English speaker relied on the self-perception of personal linguistic affinities, rather than a reflection of the scientists' English language proficiencies. Therefore, CSIRO scientists who self-identified as native English speakers were ineligible to complete the electronic survey.

Eligible respondents were asked to state the other languages they used on a daily basis, and the language in which they completed their highest education qualification. The next two questions enquired about the different types of media they used to communicate their scientific research, in English and in any other languages respectively. They were offered multiple answers, which included, among other communication venues, journal papers, conference proceedings and science shows. Next, respondents were asked to rank how important it was both personally and professionally to communicate their scientific research in English. They were then asked to rate on a ten-point scale, where ten was the highest, how skilled they felt personally to communicate science in English. Finally, the respondents were asked if they were willing to participate in a follow up interview. Of the thirteen CSIRO scientists who completed the survey, six consented to be interviewed as shown in Table 1.

In the second phase of the study, consenting survey respondents were telephoned and presented with qualitative interview questions as presented in Table 2. Conforming to a general interview guide approach [Gall, Borg and Gall, 1996, p. 309], the interviews outlined a series of topics to be explored in no specific order. The topics included their perceived science communication role as CSIRO scientists; opportunities to communicate their scientific research in English; their training needs and proficiencies to communicate science effectively in English; and the challenges they perceived when communicating science in English. Each interview evolved to suit the specific situation, for example, questions were 
paraphrased and relevant topics expanded on to fit each interview. Each interview lasted a maximum of thirty minutes. All the interviews were audio recorded and transcribed verbatim.

Table 1. Responses of the 13 CSIRO scientists surveyed.

\begin{tabular}{|l|l|l|l|l|}
\hline $\begin{array}{l}\text { Scientist } \\
\text { Code/No. }\end{array}$ & LOTE & Gender & $\begin{array}{l}\text { Self-rating- } \\
\text { English language skills }\end{array}$ & $\begin{array}{l}\text { Consent to } \\
\text { interview }\end{array}$ \\
\hline Scientist 1 & German & Female & 9 & No \\
Scientist 2 & Spanish, Catalan & Male & 8 & Yes \\
Scientist 3 & Dutch & Male & 9 & Yes \\
Scientist 4 & Russian & Male & 10 & No \\
Scientist 5 & Greek & Male & 9 & No \\
Scientist 6 & Assamese, Hindi & Male & 7 & No \\
Scientist 7 & Sinhala & Male & 8 & Yes \\
Scientist 8 & Persian & Male & 9 & No \\
Scientist 9 & Tamil & Male & 4 & Yes \\
Scientist 10 & Urdu & Female & 7 & No \\
Scientist 11 & Sinhala & Male & 5 & No \\
Scientist 12 & Chinese & Male & 9 & Yes \\
Scientist 13 & Sinhala & Male & 9 & Yes \\
\hline
\end{tabular}

Table 2. Questions explored in interviews with the six CSIRO scientists.

\begin{tabular}{|l|l|}
\hline Interview Topic & Questions \\
\hline $\begin{array}{l}\text { Perceived science communication } \\
\text { role as CSIRO scientists }\end{array}$ & $\begin{array}{l}\text { Can you tell me what your role as a scientist is at } \\
\text { CSIRO? } \\
\text { Do you think it's easy for people from all different } \\
\text { language backgrounds to do science in CSIRO? }\end{array}$ \\
\hline $\begin{array}{l}\text { Opportunities to communicate } \\
\text { scientific research in English }\end{array}$ & $\begin{array}{l}\text { Please share with me about opportunities you } \\
\text { have to communicate your scientific research? }\end{array}$ \\
\hline $\begin{array}{l}\text { Training needs and proficiencies } \\
\text { to communicate science effectively } \\
\text { in English }\end{array}$ & $\begin{array}{l}\text { You said in the survey that you are not a native } \\
\text { speaker of English. Can you tell me more about } \\
\text { how you came to speak English? } \\
\text { What do you think was the reason that you } \\
\text { decided to study science in your non-native } \\
\text { language? }\end{array}$ \\
\hline $\begin{array}{l}\text { Perceived challenges when } \\
\text { communicating science in English }\end{array}$ & $\begin{array}{l}\text { How have you dealt with any challenges in } \\
\text { your experience of communicating your science in } \\
\text { English? }\end{array}$ \\
\hline
\end{tabular}

Interview transcripts were analysed for corresponding themes in the previewed literature. Specifically, interview responses which indicated that disciplinary aspects of science can only be communicated in English; that scientific communication is best achieved in English; and/or that academic scientific publications in English advance career prospects, were coded as "corresponding to previewed literature". In addition, reoccurring ideas in the interview data that did not match these themes were separated for analysis.

\subsection{Organisational context}

Responses from CSIRO communication expert staff stated explicitly that the scientists are the Organisation's "frontline communicators" (Communication 
Experts nos. 1 \& 4), and are, therefore, the primary communicators of scientific research:

Basically it's a fundamental part of every scientist's role within CSIRO to be able to communicate their science. (Communication Expert no. 2)

They reiterated that the most prioritised media for research communication are academic journals and conference presentations. These activities constitute a large proportion of the scientists' communications and are directed primarily to inform their peers. The scientists' seniority within the Organisation and the type of research in which they were engaged determined, moreover, their priorities among different forms of communication. For instance, Communication Expert no. 2 stated that while postdoctoral researchers "would definitely be expected to publish papers" to advance their research careers, senior scientists and project leaders on industry funded projects, "would be expected to write reports".

There were inferences, however, that CSIRO scientists from non-English speaking backgrounds may be challenged by the above communication policy, which applied broadly across scientists in the Organisation. As Communication Expert no. 1 explained:

There's broader cultural questions... the opportunities broadly are the same but how empowered does the individual feel to take those, based on somebody with English as an additional language? Lots of things can influence how comfortable they're feeling about their language, whether or not they put themselves forward.

This statement recognises that the Organisation's communication policy could be challenging to scientists for whom English is a second or additional language. It potentially acknowledges deeper socio-cultural issues (i.e. "lots of things") that underpin the confidence with which scientists take charge of their communications (i.e. "whether or not they put themselves forward"). Consistent with the literature [see, for example, Charles, 2007], Communication Expert no. 1 observed that negative self-perceptions of scientists' linguistic proficiency could lead to disempowerment through questioning of their disciplinary expertise,:

People's colleagues expressing concern that for whatever reason something to do with the way someone writes or the way they speak is making them unhappy or it's meaning they're missing out on opportunities or not putting themselves out for opportunities.

\subsection{Organisational awareness of non-Anglophone scientists' issues}

There is broad awareness within CSIRO Communication Experts that while support is available, non-Anglophone scientists may be challenged by the Organisation's communication policy and this could affect how these scientists choose to communicate their research. As described in the background to this study, CSIRO has an Equal Opportunity Program, enabling equitable employment of staff from diverse cultural and linguistic backgrounds. In addition, CSIRO has in place an Organisation-wide "Diversity and Inclusion Strategy ... for initiatives 
specifically for people from non-English speaking backgrounds" (Communication Expert no. 1), to further enable the equal participation of non-Anglophone scientists in its communication activities.

The above Strategy feeds into different initiatives within the Organisation, which includes a Learning and Development Team to conduct regular courses. Communication Expert no. 2 stated these courses are specifically designed to improve the language and communication skills of non-Anglophone scientists. The two courses they currently run include "one for speaking English and one for writing English for non-native speakers" that are consistent with recommendations in literature to provide specific training for non-Anglophone scientists to communicate their science effectively in English [Colburn and Nguyen, 2012; Ferguson, Pérez-Llantada and Plo, 2011].

The Learning and Development Team courses, it appeared, played two important roles to reinforce the Organisation's communication policy. First, the courses provided language and communication support to non-Anglophone scientists within CSIRO. Second, and equally important, the courses helped ensure that all scientists had the necessary English language skills to function as frontline communicators for the Organisation. According to Communication Experts no. 4 and 2, respectively:

Editing and approving scientific papers is the responsibility of a staff member's line manager, with possibly an external editor being brought in if required.

If the scientists can't write about or present their science then that has a huge effect on the team as well. Because other people have to pick up and write for them.

It is clear therefore, that effective communication skills in English are desired for all staff by CSIRO, in line with the Organisation's communication policy. As evidenced by the Communication Experts above, non-Anglophone scientists may have more difficulty in achieving this goal compared to their Anglophone colleagues. Non-Anglophone scientists could end up struggling to match the required standard, with possible implications for future work and their standing within the team. This experience, discussed with the scientists in the next section, expands upon elements of linguistic hegemony mentioned in 1.1. of this paper.

\subsection{Limitations}

We concede limitations in the present study, given its preliminary nature. First, this study investigated scientists within one particular organisation, premising that it would offer a univariate by eliminating communication differences across different organisational cultures. Exploring the perspectives of non-Anglophone scientists from multiple research organisations in Australia may offer additional perspectives.

Second, the issues of bilingualism and associated multicultural identities [see Wierzbicka, 2014] were not discussed in this study, in order to make the preliminary explorations manageable. Although the participating scientists could certainly be defined as bilingual, further enquiries need to explore how their 
multicultural perspectives inform their communication choices. Such investigations may be especially relevant in geopolitical distributions of multilingual populations, for example in Quebec or India.

Third, there is room to explore further the diversity among non-Anglophone scientists in societies where English is the first language, including within CSIRO itself at a larger scale. These explorations will provide opportunities to further analyse the roles and functions of identity and its constituents in the context of linguistic preferences and academic science communication aptitude.

Fourth, only two scientists who participated in the online survey were female, while the six scientists who consented to be interviewed were all male. Research documents extensively the influence of gender on scientific participation [see, for example, Hayes and Tariq, 2000], including different gender preferences for scientific disciplines [Rhoten and Pfirman, 2007]. It is unclear, therefore, what role gender played in the present study. Further research in this area needs to ensure representation of people of different genders to understand fully the communication behaviours of non-Anglophone scientists.

Fifth, it was not within the scope of this study to fully describe the diversity of non-Anglophone communities marginalized by conventional western science, in particular indigenous and non-western communities whose knowledge systems do not have an Anglophone voice [Whitt, 2009; Huttner-Koros, 2015]. Indigenous populations in Australia and around the world provide unique perspectives in terms of scientific knowledge and acceptance within the scientific community that require further investigation.

Sixth, this study has followed current practice in the literature and employed interchangeably a vast nomenclature to describe individuals who are not first language speakers of English. It is not possible within the scope of this study to remedy the contention of multiple terminologies. We wish to point out, however, that such attempts to define identity based solely on language usage offers a limited outlook, and calls for a more accurate descriptor for the other.

Results and discussion

\subsection{Importance of English}

All thirteen survey respondents indicated that they believed it was "very important" professionally to communicate scientific research in English. They explained it entailed benefits, such as greater visibility in international scientific literature, and better connectivity with scientists internationally. As Scientist no. 2 elaborated in the interview:

I think the main niche of doing research is the visibility of your work... And I guess that it's much more easy to get a huge visibility if you [wrote] your work in English and communicated in English.

The link drawn previously in the literature between academic publications in English and enhanced career prospects [see Ljosland, 2011], was evidenced in this study by Scientist no. 13, who stated that "scientific publications in English are a 
performance metric". This places, as Hwang [2005] expressed earlier in section 1.3., an extra demand on non-Anglophone scientists to develop effective academic communication skills in English. The present study revealed personal stories about competitive career advancement, enabled by better academic communication proficiency in English. As Scientist no. 3 explained, for example:

I followed a publishing in English course in [my country of origin]... It's not common, most people just learn from their supervisors... which actually put me quite ahead of some of my fellows [i.e. fellow scientists], so in fact I had some advantage there.

As non-native English speakers, the scientists described benefits of communicating their research in English. Consistent with perceptions documented in the literature [see, for example, Wierzbicka, 2014], they identified that English is the most viable medium for their research, mainly because their native languages were incapable of matching the lexical detail of academic English:

\begin{abstract}
English is the only way for science... I can communicate my research in my language, but sometimes I have to use English for certain terms, which I will not be able to translate completely in my native language. (Scientist no. 9)

Among colleagues we rarely spoke in English while at university, but while we were discussing the course material we were using the English terminology, but still conversing in my native language. (Scientist no. 13)

I couldn't work in my native language, it doesn't have the technical or academic vocabulary... [although] I would speak [in my native language] to my supervisors... all the writing is in English. (Scientist no. 3)
\end{abstract}

Accordingly, nine of the survey respondents stated they only communicated their scientific research in English. This group relied heavily on journal papers, conferences, research supervision, lectures and presentations to communicate their research. Four of the survey respondents, who used both English as well as their native languages, also communicated their research through blog posts, science shows and public lectures. The fact that all thirteen scientists had completed their highest tertiary level qualifications in English and only four of them engaged in communicating their research outside academic realms in languages other than English, resonated with the literature. As observed previously with reference to Goonatilake [1987] in section 1.3. of this paper, non-Anglophone scientists are trained to communicate predominantly to first language English audiences. The larger proportion of scientists in this study chose to communicate their research exclusively in English. This reinforces the view that there is a linguistic exclusivity of English for scientific discourse, a view that is sustained, at least in this situation, by the scientists' ongoing professional communications in a first language English speaking workplace:

At CSIRO... we always talk in English, since we already do all our interviews when we apply for our positions in English (Scientist no. 2)

According to Spolsky [2004], it is evident that linguistic imperialism of this type benefits mainly Anglophone culture, with marginal, if any, benefit to other 
language speaking groups. For science, this would imply that words and ideas which have been used in other languages to describe, share and inform understandings of the world would gradually be lost: a phenomenon known as domain collapse [Mühlhäusler, 2011]. Domain collapse has been explored, for example, in the Swedish language by Boyd [2001], who states there has been "a weakening of Swedish in Sweden due to the influx of other languages, primarily English, into domains such as education, science, information technology" [p. 190].

\subsection{Expectations of training and support}

The difficulties non-Anglophone scientists encounter extend beyond simple linguistic proficiency in English, often encompassing elements of personal identity stemming from their non-native English speaking status [Flowerdew, 1999a; Hwang, 2005; Hwang, 2013]. Even with additional efforts, they are unconvinced that they will be able to master English language skills comparable with those of native speakers of the language. Despite CSIRO's organisational onus on the Learning and Development Team courses, it is possible to speculate they may only partially address the communication challenges of non-Anglophone scientists. It was useful, therefore, for this case study to examine the scientists' expectations of training and support that were offered by CSIRO.

In the survey, ten respondents agreed they wanted to improve their communication skills. Seven of these scientists identified specifically that they wanted training and support in academic science communication. Overall, their interview responses presented an overwhelming need for training, as one scientist commented at the end of the interview:

[It is] good to know that I am not the only person struggling in this area [i.e. scholarly communications in English]... If you [i.e. the present study] can suggest some solutions or some ways for us [i.e. CSIRO scientists] to train that would be a good idea. (Scientist no. 9)

There was, however, a lack of awareness among some of the scientists about specialist training provided to support scholarly communications, in particular for non-Anglophone scientists.

Q: Is there support at CSIRO specifically for non-native speakers of English?

That I am not quite sure, not what I am aware of. (Scientist no. 12)

Some interview respondents did allude to the possibility of such programs existing, and that they would be best suited to scientists from language backgrounds other than English:

Q: Is there support available at CSIRO to improve your communications skills?

If I have a to do a media presentation or anything, they are very keen to help out making the interview format or sending some documents so they are helping a lot. (Scientist no. 9) 
I am sure CSIRO has the same support as most [research] universities... There is quite a lot of international staff [at CSIRO] and staff development offers small workshops and training programs. I assume that the people taking those workshops are non-native English speakers. (Scientist no. 7)

These findings corresponded, however, only marginally with the scientists' self-rating of their research communication skills in English. The thirteen survey respondents scored an average rating of 7.92 on the ten-point scale, where "highly-skilled" was rated ten; thus implying they possessed a relatively high self-efficacy to communicate science in English. The apparent tension between their perceived ability and their overwhelming desire for training and support can be linked to the comments underlying those scores. These comments may draw attention to the respondents' non-native English speaking status:

There is always that feeling that I am less efficient when communicating in English than a native speaker. (Scientist no. 2)

It is hard to understand [scholarly communication] being non-native to English. (Scientist no. 10)

Sometimes I struggle while conveying the message through journals... You have to know how to write an article if you get some good results... And the article it has to be in passive voice right? Sometimes I struggle, sometimes my problem is this they say 'oh this particular sentence you wrote is active', so I have some kind of issue with converting the active into passive voice. (Scientist no. 9)

These remarks resonate with findings cited earlier from Hong Kong [Flowerdew, 1999a] and South Korea [Hwang, 2005] where English is not the first language. Moreover, the responses by Scientists nos. 2, 9 and 10 are indicative of the struggle non-Anglophone scientists face with scholarly communication in societies where English is the first language.

\subsection{Proficiency to communicate versus linguistic aptitude in English}

The scientists identified that a crucial challenge when attempting academic science communication in English was their limited English language vocabulary.

Q: Are there any challenges you have to deal with publishing your research?

When I started out [as a scientist] I had a lot of trouble writing... partly finding words and building up vocabulary, academic vocabulary... I still find it sometimes quite hard. (Scientist no. 3)

Their interviews particularly emphasised this limitation when they were tasked with verbal communication, such a conference presentations. According to Scientist no. 2:

If you need to do it in a second language... it's a bit more tricky... if you have to give a presentation. The problem is finding the correct words... You can practise your presentation as many times... you can [even] memorise it... The tricky part starts when the questions arise. Then you need to be able to communicate in real time. 
One means of overcoming the challenge of limited English vocabulary, Scientist no. 7 explained, was to "get support from people who know more"; namely first language English speakers.

Some interviews, however, drew a distinction between aptitude in English and being able to communicate proficiently in the language, as Scientist no. 3 remarked:

I don't feel that my language background is really a consideration... it's more that I lack the experience to explain things in a simple way... it is not related the English... even though you are very fluent, very good in English, you learn that there is a lot more that you can learn when you're surrounded on a daily basis by native speakers.

The above response seems to disestablish the perception that better scholarly scientific communication requires greater English language ability. Instead, it may suggest the need to learn by emulating the best communication practice of native speakers and of more experienced academics. Emulation, as pointed out previously [see, Sacks, 1996, in 1.3.], encompasses other elements of Anglocentric culture that underpin specific forms of language usage. This view was confirmed in another interview, which stated that proficiency to engage in effective scholarly communication relied, among other aspects, on one's fluency in discipline-specific terminology in English.

\begin{abstract}
Q: Do you think that your issue with technical terms in your discipline comes from English not being your native language?

It probably doesn't have anything to do with the native language. It is to do with the technical area that you are in. When you are in a technical area for a while there's certain technical terms that you sort of assume are universally known. (Scientist no. 13)
\end{abstract}

As explained in the literature, native English speakers assume a universal social cognition for scientific terminology [see, for example, Dowrick, 2004]. It appears the scientists in our study were subscribing to this ideology. They admit to being acclimatised to discipline-specific terminology dictated by the Anglophone hegemony in science, while oblivious to the Anglocentric socio-cultural distinctions that are emphasised ultimately. Encapsulating this perspective is a response from Scientist no. 2:

Q: Do you think you would be able to talk about your research in your native language?

The main issue is that those technical words that you start learning in English, and you never realise a lot of the translation itself... Usually when you hear a translated word [in my native language], it's so weird that you don't use it and you use just the English terminology.

\title{
3.4 Identity issues
}

We found clear instances of identity conflict in some of the interviews with scientists. These perceptions appeared to underlie the language-based challenges 
that confronted them. This prompted further exploration into the identity issues that non-Anglophone scientists grapple with when they relocate permanently to first language English societies.

For example, one scientist stated that although English was not his first language, he had been "learning English since kindergarten" and completed his secondary education in "a private school where English was more commonly used than in state schools" in his country. Despite his early exposure and having communicated science actively in English for more than a decade, he argued that:

\begin{abstract}
Obviously it's not like [my] mother language... when I first started writing proper scientific literature, I always made sure I sent it to a native English speaker and got it proof read before I actually sent it to a journal. I still do that, I will still do that actually, because it's not the same, like you know the content but to express that I still seek support from native English speakers when I write. (Scientist no. 7)
\end{abstract}

The relationship between English language proficiency and professional scientific identity is a contentious one [Charles, 2007]. Based on the literature reviewed previously, the above statement could be interpreted in two ways. First, that the linguistic nuances in science communicated in English are best achieved by native speakers of the language [Harré, 2012]. Because the above scientist is not a native English speaker, he may choose, therefore, to seek assistance from one who is. Second, that a linguistic hegemony prevalent in science and scholarly scientific communication is the purview of native English speakers [Mauranen, Hynninen and Ranta, 2010]. Therefore, the scientist in this instance may appear to seek permission, by presubmitting to the linguistic authority of a native English speaker.

We contend there could be a third explanation, one that is grounded in professional identity. Perera [2011] found that non-Western science teachers conversant in Western scientific ideologies assumed a privileged status over their contemporaries. The assimilation of elements from Western culture into the teachers' professional identity seemed to elevate them from their peers who lacked Western scientific training. Similarly, the proficiency to communicate in English may advantage non-native speakers over their peers who lacked opportunities to communicate frequently in English. This may be evidenced in Scientist no. 7's reference to a private school education where English language was more commonplace. However, we suggest that as a non-Anglophone scientist, the scientist may struggle to maintain a professional identity congruent with an Anglophone scientist.

The above scientist is not a solitary example of identity conflict. In an attempt to perhaps consolidate their professional identity with English language proficiency, two scientists expressly differentiated their (non-Anglophone) home countries from other countries where English is not the first language. We believe the scientists may have found it necessary to differentiate in this way to justify better access to English, and by extension better professional identity, compared to other non-Anglophone contemporaries.

I think in the case of [my country of origin], majority of people are quite well versed in English, so maybe it's a slightly different situation than in some other countries where, 
for example, higher education is done in the native language. So I think that makes a big difference to a scientist... (Scientist no. 13)

For a long time [my country of origin] had been ruled by the British, so that influences us to learn English, even better than other countries where English is spoken.

(Scientist no. 9)

The above responses correspond with the concept of legitimation crisis that has been broadly used by Baumeister, Shapiro and Tice [1985] to classify forms of identity conflict, where an individual has more than one binding element to their identity. Given the strong relationship between language and an individual's identity [see Jameson, 2007], it is possible to deny challenges associated with communicating in a particular language, especially if that language plays a crucial role in identity formation [see also Hwang, 2005].

In a separate interview, a scientist stated that his laboratory team at CSIRO was multinational, and included European scientists, but there were "not many Australians" (i.e. first language English speakers). He pointed out, therefore, "it's quite easy to deal with people [like himself] who use English as a second language". Their collective identity as speakers of English as a second language, the scientist informed, allowed them to ignore the otherwise prevalent authority of native English speakers. They were able, therefore, to perceive their professional identities differently; i.e. not in conflict with the Anglophone identities of their professional scientific workplace. According to Jameson [2007], an individual's identity is constructed through a multitude of "formal or informal membership in groups... affected by close relationships, and negotiated through communication" [p. 199]. Aptitude in a certain language, or in this instance limited proficiency to communicate in English can, therefore, define individuals' belonging to a professional group that is subsumed under the Anglophone hegemony of scholarly science communication.

The Anglophone hegemony in science creates a difficult communication space for scientists from non-English speaking backgrounds. The preliminary explorations described in the present study identified themes that resonated with previous research, which have until now investigated this communication space from the perspectives of non-Anglophone scientists in their home countries. These paradigms contain pervasive ideas that science is best communicated in English. For reasons of career success and their belief that the best scientific research is published in English, scientists from non-English speaking backgrounds feel compelled to communicate academically in English.

In addition, we found that the perspectives of non-Anglophone scientists who continue to engage in research in Australia, where English is the first language, add complexity to the existing body of research. The present case study of nonAnglophone scientists at CSIRO reveals a complex science communication space, where English language aptitude alone is insufficient to engage effectively in scholarly communication. The CSIRO scientists in this study were constrained by their self-perceptions of being from non-Anglophone backgrounds, which, despite their best efforts, were perceived as inferior in comparison to the dominant Anglocentric presence in science. This study has shown that the imperative to communicate 
scientific research in English defines a landscape comprising deeper perceptions of identity, that are entwined professionally and socio-culturally. The apparent Anglophone hegemony of this realm is both a curtain and a backdrop to the metaphorical stage of scholarly science communication: it is a screen that restricts access, as well as the milieu against which non-Anglophone scientists perform.

Australian Bureau of Statistics (ABS) (6th June 2014). Australia's Population by Country of Birth 2013. URL: http: //www . abs . gov . au/.

Australian Government (2012). Prime Minister's Expert Panel on Asylum Seekers Report. Canberra, Australia: Refugee Council of Australia.

URL: http://www.refugeecouncil.org.au/r/rpt/2012-Expert-Panel.pdf (visited on 21st July 2014).

Bauman, R. and Briggs, C. L. (2003). Voices of Modernity: Language Ideologies and the Politics of Inequality. Cambridge, New York, U.S.A.: Cambridge University Press.

Baumeister, R. F., Shapiro, J. P. and Tice, D. M. (1985). 'Two kinds of identity crisis'. Journal of Personality 53 (3), pp. 407-424. PMID: 4067788.

Bennett, K. (2010). 'Academic discourse in Portugal: A whole different ballgame?' Journal of English for Academic Purposes 9 (1), pp. 21-32. DOI: $10.1016 / \mathrm{j}$. jeap. 2009.11.002.

Boyd, S. (2001). 'Immigrant Languages in Sweden'. In: The Other Languages of Europe: Demographic, Sociolinguistic and Educational Perspectives. Ed. by G. Extra and D. Gorter. Clevedon, U.K.: Multicultural Matters, pp. 177-193.

Charles, M. (2007). 'Language Matters in Global Communication Article Based on ORA Lecture, October 2006'. Journal of Business Communication 44 (3), pp. 260-282. DOI: 10.1177/0021943607302477.

Colburn, A. and Nguyen, H. T. (2012). 'Every word you speak: Helping English language learners swim in the science language stream'. The Science Teacher 79, pp. 58-61.

Commonwealth Scientific and Industrial Research Organisation (CSIRO) (2015). Guidelines for Applicants. URL: http://www . csiro. au/en/About/Our-impact/Re porting-our-impact/Annual-reports/14-15-annual-report/Part2/Perform ance-portfolio/Program-1.

Crystal, D. (2003). English as the global language. Cambridge, U.K.: Cambridge University Press.

Dowrick, C. (2004). Beyond Depression: A New Approach to Understanding and Management. Oxford University Press.

Dunbar, R. (1996). Grooming, Gossip, and the Evolution of Language. Cambridge, MA, U.S.A.: Harvard University Press.

Ferguson, G., Pérez-Llantada, C. and Plo, R. (1st March 2011). 'English as an international language of scientific publication: a study of attitudes'. World Englishes 30 (1), pp. 41-59. DOI: 10.1111/j.1467-971X.2010.01656.x.

Flowerdew, J. (1999a). 'Problems in writing for scholarly publication in English: The case of Hong Kong'. Journal of Second Language Writing 8 (3), pp. 243-264. DOI: 10.1016/S1060-3743(99)80116-7.

- (1999b). 'Writing for scholarly publication in English: The case of Hong Kong'. Journal of Second Language Writing 8 (2), pp. 123-145. DOI: 10.1016/S1060-3743(99)80125-8.

Gall, M. D., Borg, W. R. and Gall, J. P. (1996). Educational Research. 6th ed. White Plains, New York, U.S.A.: Longman Publishers.

Gondwe, M. and Longnecker, N. (2015). 'Objects as Stimuli for Exploring Young People's Views about Cultural and Scientific Knowledge'. Science, Technology E Human Values 40 (5), pp. 766-792. DOI: 10.1177/0162243915577452. 
Goonatilake, S. (1987). 'Aborted Discovery: Science and Creativity in the Third World'. Technology and Culture 28, pp. 899-901.

Harré, R. (2012). 'Methods of Research: Cultural/Discursive Psychologies. Chapter 2.' In: Psychology for the Third Millennium: Integrating Cultural and Neuroscience Perspectives. Ed. by R. Harré and F. Moghaddam. London, U.K.: SAGE Publications Ltd, pp. 22-36. DOI: 10.4135/9781446288542.n2.

Hayes, B. C. and Tariq, V. N. (2000). 'Gender differences in scientific knowledge and attitudes toward science: a comparative study of four Anglo-American nations'. Public Understanding of Science 9 (4), pp. 433-447. DOI: $10.1088 / 0963-6625 / 9 / 4 / 306$.

Hofstede, G. (2001). Culture's consequences: Comparing values, behaviors, institutions, and organizations across nations. Thousand Oaks, California, U.S.A.: Sage Publications.

Huttner-Koros, A. (2015). 'The Hidden Bias of Science's Universal Language'. The Atlantic. URL: http://www.theatlantic.com/science/archive/2015/08/engli sh-universal-language-science-research/400919/.

Hwang, K. (2005). 'The Inferior Science and the Dominant Use of English in Knowledge Production A Case Study of Korean Science and Technology'. Science Communication 26 (4), pp. 390-427. DOI: 10.1177/1075547005275428.

- (2013). 'Effects of the Language Barrier on Processes and Performance of International Scientific Collaboration, Collaborators' Participation, Organizational Integrity, and Interorganizational Relationships'. Science Communication 35 (1), pp. 3-31. DOI: 10.1177/1075547012437442.

Jameson, D. A. (2007). ‘Reconceptualizing Cultural Identity and Its Role in Intercultural Business Communication'. Journal of Business Communication 44 (3), pp. 199-235. DOI: 10.1177/0021943607301346.

Ljosland, R. (2011). 'English as an Academic Lingua Franca: Language policies and multilingual practices in a Norwegian university'. Journal of Pragmatics 43 (4), pp. 991-1004. DOI: $10.1016 / \mathrm{j}$. pragma. 2010.08.007.

Mauranen, A., Hynninen, N. and Ranta, E. (2010). 'English as an academic lingua franca: The ELFA project'. English for Specific Purposes 29 (3), pp. 183-190. DOI: $10.1016 / \mathrm{j}$.esp. 2009.10.001.

Meneghini, R. and Packer, A. L. (2007). 'Is there science beyond English? Initiatives to increase the quality and visibility of non-English publications might help to break down language barriers in scientific communication'. EMBO Reports 8 (2), pp. 112-116. DOI: 10.1038/s j . embor. 7400906. PMID: 17268499.

Merriam-Webster (22nd June 2016). Anglophone - Definition. URL: http://www . merriam-webster. com/dictionary/anglophone.

Mühlhäusler, P. (2011). 'Ecolinguistics, Linguistic diversity, ecological diversity'. In: The Postcolonial Science and Technology Reader. Ed. by S. Harding. North Carolina, U.S.A.: Duke University Press, pp. 198-210.

Myles, J. and Cheng, L. (2003). 'The social and cultural life of non-native English speaking international graduate students at a Canadian university'. Journal of English for Academic Purposes 2 (3), pp. 247-263. DOI: $10.1016 / \mathrm{S} 1475-1585(03) 00028-6$.

Obeyesekere, G. (1985). 'Depression, Buddhism, and the Work of Culture in Sri Lanka'. In: Culture and Depression: Studies in the Anthropology and Cross-cultural Psychiatry of Affect and Disorder. Ed. by A. Kleinman and B. Good. Berkeley, U.S.A.: University of California Press, pp. 134-152.

Perera, S. (2011). 'Science teachers from non-Western backgrounds challenged by Western science: A whole other ball game'. The International Journal of Science in Society 2, pp. 11-22. 
Rhoten, D. and Pfirman, S. (2007). 'Women in interdisciplinary science: Exploring preferences and consequences'. Research Policy 36 (1), pp. 56-75. DOI: $10.1016 / \mathrm{j}$.respol .2006.08.001.

Sacks, O. (1996). The Island of the Colour-blind. Sydney, Australia: Picador.

Searle, S. (2014). How do Australians engage with science? Preliminary results from a national survey. Australian National Centre for the Public Awareness of Science (CPAS): The Australian National University. URL: http://diffusion.weblogs . anu.edu.au/files/2014/05/Searle-S.D. - 2 014.-How-do-Australians-engage-with-science.-April-2014.pdf (visited on 10th August 2014).

Shweder, R. A. (2012). 'Anthropology's Disenchantment With the Cognitive Revolution1'. Topics in Cognitive Science 4 (3), pp. 354-361. DOI: $10.1111 / j .1756-8765.2012 .01199 . x$.

Spolsky, B. (2004). Language Policy. New York, U.S.A.: Cambridge University Press.

Swales, J. (1990). Genre Analysis: English in Academic and Research Settings. Cambridge, U.K.: Cambridge University Press.

Van Leeuwen, T. N., Moed, H. F., Tijssen, R. J. W., Visser, M. S. and Van Raan, A. F. J. (2001). 'Language biases in the coverage of the Science Citation Index and its consequences for international comparisons of national research performance'. Scientometrics 51, pp. 335-346.

Vass, A., Mitchell, A. and Dhurrkay, Y. (2011). 'Health literacy and Australian Indigenous peoples: an analysis of the role of language and worldview'. Health Promotion Journal of Australia 22 (1), pp. 33-37. PMID: 21717835.

Whitt, L. (2009). Science, Colonialism, and Indigenous Peoples: The Cultural Politics of Law and Knowledge. Cambridge, U.K.: Cambridge University Press. Wierzbicka, A. (2014). Imprisoned in English: The Hazards of English as a Default Language. New York, U.S.A.: Oxford University Press.

Adam Huttner-Koros holds a joint Bachelor of Science and Bachelor of Arts Degree, awarded in 2014 by The Australian National University, Canberra. His studies and subsequent research have focused on science communication and linguistics. His particular interests are the interactions between science and languages within wider societal contexts. E-mail: adam_huttner_@hotmail.com.

Sean Perera is a Lecturer at The Australian National University's Centre for the Public Awareness of Science in Canberra, where he earned his Ph.D. in science communication in 2010. His research and teaching focus on communicating science cross culturally. He explores issues in formal and informal science learning from the perspectives of culturally and linguistically diverse audiences.

E-mail: Sean.Perera@anu.edu.au.

How to cite

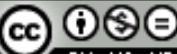

